\title{
Análise do potencial de biomassa residual no Algarve, Portugal, baseada em SIG
}

\author{
Jéssica Torres Rocha ${ }^{1}$, Isabel Malico ${ }^{2,3}$, Ana Cristina Gonçalves ${ }^{4}$, Adélia Maria de Oliveira Sousa ${ }^{4}$ \\ ${ }^{1}$ Engenharia Sanitária e Ambiental, Universidade Federal do Mato Grosso, Cuiabá, Mato Grosso, Brasil. \\ ${ }^{2}$ IDMEC, Instituto Superior Técnico, Universidade de Lisboa, Lisboa, Portugal \\ ${ }^{3}$ Departamento de Física, Universidade de Évora, Évora, Portugal. \\ ${ }^{4}$ Departamento de Engenharia Rural, Escola de Ciências e Tecnologia, Instituto Mediterrânico \\ de Agricultura, Ambiente e Desenvolvimento, Instituto de Investigação e Formação Avançada, \\ Universidade de Évora, Évora, Portugal
}

\begin{abstract}
RESUMO O presente estudo avalia o potencial dos resíduos florestais (azinheira, sobreiro, eucalipto, pinheiro bravo, pinheiro manso e castanheiro), parte dos agrícolas (olival e vinhas) e biomassa proveniente de matos e espécies invasoras na região do Algarve, Portugal, e mapeia sua disponibilidade em um raio de coleta de $30 \mathrm{~km}$ em torno de todos os pontos de uma malha de $250 \mathrm{~m}$ de tamanho de célula que cobre a região. Foi utilizado um Sistema de Informação Geográfica (ArcGIS), o mapa de uso do solo de Portugal e as produtividades de resíduos das espécies de interesse publicadas por outros autores. Se obteve um potencial total de biomassa residual para o Algarve de $96.905 \mathrm{t}$ seca/ano, das quais $65.543 \mathrm{t}$ seca/ano provêm de florestas, se destacando as florestas de pinheiro manso (25,0\%) e de eucalipto (19,5\%), e 26.322 t seca/ano (27,2\%) de matos. Na região centro-oeste do Algarve foi onde se atingiram valores de biomassa residual acima de $30 \mathrm{kt} \mathrm{seca/ano} \mathrm{para} \mathrm{uma} \mathrm{área} \mathrm{de} \mathrm{coleta} \mathrm{de} \mathrm{raio} \mathrm{de} 30 \mathrm{~km}$. A quantidade de resíduos indica, do pondo de vista da disponibilidade de recurso, que é possível abastecer pequenas/médias centrais de valorização energética de biomassa residual a implementar na região.
\end{abstract}

Palavras-chave: Bioenergia; energias renováveis; resíduos; recurso; disponibilidade de biomassa.

\section{GIS-based analysis of the residual biomass potential in the Algarve, Portugal}

\begin{abstract}
This paper focuses on the evaluation, for the Algarve, Portugal, of the residual biomass potential of forests (holm and cork oaks, eucalyptus, maritime and stone pines and chestnut) and farmlands (olive grove and vineyards) and of the biomass of scrublands and invasive species. Biomass availability is mapped in a collection area with $30 \mathrm{~km}$ radius around the points of a grid with $250 \mathrm{~m}$ cell size, which covers the entire region. A Geographical Information System (ArcGIS) was used, along with the land cover map of Portugal and the residual yields for the species of interest obtained from the literature. The total residual biomass potential obtained for the Algarve was 96,905 t dry/year, of which 65,543 t dry/year comes from forests, especially from stone pine (25\%) and Eucalyptus spp. forests (19.5\%), and 26,322 t dry/year (27.2\%) from scrubland. In the central-east region of the Algarve, values of residual biomass above $30 \mathrm{kt}$ dry/year were reached for a collection area of $30 \mathrm{~km}$ radius. As far as resource availability is concern, this study indicates that it is possible to supply small/medium-size residual biomass energy valorization plants in the region.
\end{abstract}

Keywords: Bioenergy; renewable energy; residues; resource; biomass availability. 


\section{Introdução}

A biomassa é uma fonte renovável de energia que está atraindo cada vez mais atenção, pois ao contrário dos combustíveis fósseis, a taxa líquida de emissão de dióxido de carbono $\left(\mathrm{CO}_{2}\right)$ durante a combustão da biomassa é a mesma que a do $\mathrm{CO}_{2}$ absorvido durante o crescimento da massa florestal equivalente (LÓPEZ-RODRÍGUEZ et al., 2009). Portanto, a contribuição da queima da biomassa para o efeito estufa pode ser considerada insignificante, o que demonstra a necessidade de mais pesquisas da mesma como fonte de energia (LÓPEZ-RODRÍGUEZ et al., 2009) e da promoção da sua utilização.

Segundo a Diretiva 2009/28/CE de 23 de abril de 2009, se entende por biomassa, “a fração biodegradável de produtos, resíduos e detritos de origem biológica provenientes da agricultura (incluindo substâncias de origem vegetal e animal), da exploração florestal e de indústrias afins, incluindo da pesca e da aquicultura, bem como a fração biodegradável de resíduos industriais e urbanos" (UE, 2009). Desta forma, são fontes de biomassa os vegetais não-lenhosos (sacarídeos, celulósicos, amiláceos, aquáticos) e lenhosos (madeiras), resíduos orgânicos (agrícolas, urbanos e industriais) e também biofluidos como os óleos vegetais (WILLIAMS et al., 2015).

A União Europeia (UE), através da Diretiva 2009/28/CE relativa à promoção da utilização de energia proveniente de fontes renováveis, estabeleceu uma quota obrigatória de 20\% de Fontes de Energias Renováveis (FER) no consumo global de energia da UE a atingir em 2020, e uma quota de 10\% de energia proveniente de FER no setor dos transportes de todos os Estados-Membros para o mesmo ano. Em 2018, Comissão, Parlamento e Conselho Europeus alcançaram um acordo político para uma quota de 32\% de FER para a UE em 2030. Esse acordo tem ainda de ser formalmente adotado.
O uso de resíduos de biomassa contribui para a quota de fontes renováveis para a produção de energia, para além de reduzir as importações de combustíveis fósseis e, simultaneamente, o risco de incêndios florestais. A biomassa é uma fonte de energia local disponível na maioria dos países, com possibilidade de atender a uma variedade de necessidades de energia, incluindo geração de eletricidade, aquecimento do ambiente, abastecimento de veículos e fornecimento de calor de processo para instalações industriais (FERNANDES; COSTA, 2010).

A quota mundial de energias renováveis no consumo de energia final foi estimada em 2015 em 19,3\%, sendo que $73,1 \%$ desta contribuição veio da biomassa e desta, $66,3 \%$ foi consumida no setor de aquecimento, $2,1 \%$ no setor de energia e 4,7\% no setor de transportes (REN21, 2017). Em relação a Portugal, as energias renováveis representavam, em 2016, 97\% do total de produção de energia primária, demonstrando a importância das mesmas para o país (EUROSTAT, 2018). No mesmo ano, $31 \%$ do consumo de energia final português proveio de FER; destas 51\% são biomassa (DGEG, 2018).

De acordo com o $6^{\circ}$ Inventário Florestal Nacional (IFN6), o uso do solo dominante em Portugal em 2010 foi de floresta, correspondendo a $35,4 \%$ do território continental, com 3.154.800 ha, sendo o eucalipto a principal ocupação florestal com uma área de 812.000 ha, seguida pelo sobreiro (737.000 ha) e pinheiro•bravo (714.000 ha) (ICNF, 2013). Matos e pastagens também representaram uma fração significativa do uso do solo em 2010, correspondendo a $32 \%$, sendo $52 \%$ destes ocupados por matos, abrangendo uma área de 1.500.157 ha (ICNF, 2013).

Um dos obstáculos à implementação de mais sistemas de energia baseados em biomassa é a incerteza de uma oferta regular de biomassa aos consumidores (TAIBI et al., 2012), estando a viabilidade dos projetos sempre dependente da disponibilidade de biomassa e da gestão da sua cadeia de 
fornecimento (LÓPEZ-RODRÍGUEZ et al., 2009). Neste contexto, diversos estudos focam a determinação da disponibilidade da biomassa em diversas regiões (e.g., ALFONSO et al., 2009; LÓPEZ-RODRÍGUEZ et al., 2009; FERNANDES; COSTA, 2010; MESQUITA et al., 2018; BRASIL et al., 2018). Sendo um dos principais problemas de gestão da biomassa o custo associado às atividades de coleta $\mathrm{e}$ transporte, a integração da biomassa no planejamento energético de uma região requer o desenvolvimento de ferramentas de planejamento avançadas que viabilizem a avaliação e otimização dos custos econômicos, para que seja possível identificar os locais ideais para os investimentos de biomassa (LÓPEZ-RODRÍGUEZ et al., 2009; FERNANDES; COSTA, 2010).

Nesse contexto, o presente estudo tem como objetivo principal avaliar, por meio de Sistemas de Informação Geográfica (SIG), o potencial, na região do Algarve, da biomassa dos resíduos florestais da azinheira, do sobreiro, do eucalipto, do pinheiro bravo, do pinheiro manso e do castanheiro; dos resíduos agrícolas dos olivais e das vinhas, bem como da biomassa proveniente do corte de matos e de espécies invasoras. Complementarmente, foi feita a avaliação da biomassa disponível numa área de coleta com raio de $30 \mathrm{~km}$ ao redor dos pontos de uma malha regular com $250 \mathrm{~m}$ de resolução espacial que cobre toda a região do Algarve.

\section{Materiais e Métodos}

\section{Área de Estudo}

O Algarve, representado na Figura 1, é uma região de Portugal que coincide com o Distrito de Faro, com uma área de $5.412 \mathrm{~km}^{2}$ e população de 451.005 habitantes (Censo de 2011); é uma importante região turística de Portugal e da Europa. Possui clima temperado mediterrânico, caracterizado por invernos amenos e curtos e verões longos, quentes e secos. A região do Alentejo (sub-regiões do Alentejo Litoral e do Baixo Alentejo) está ao norte do Algarve, o oceano Atlântico ao sul e oeste e a leste o Rio Guadiana marca a fronteira com a Espanha.

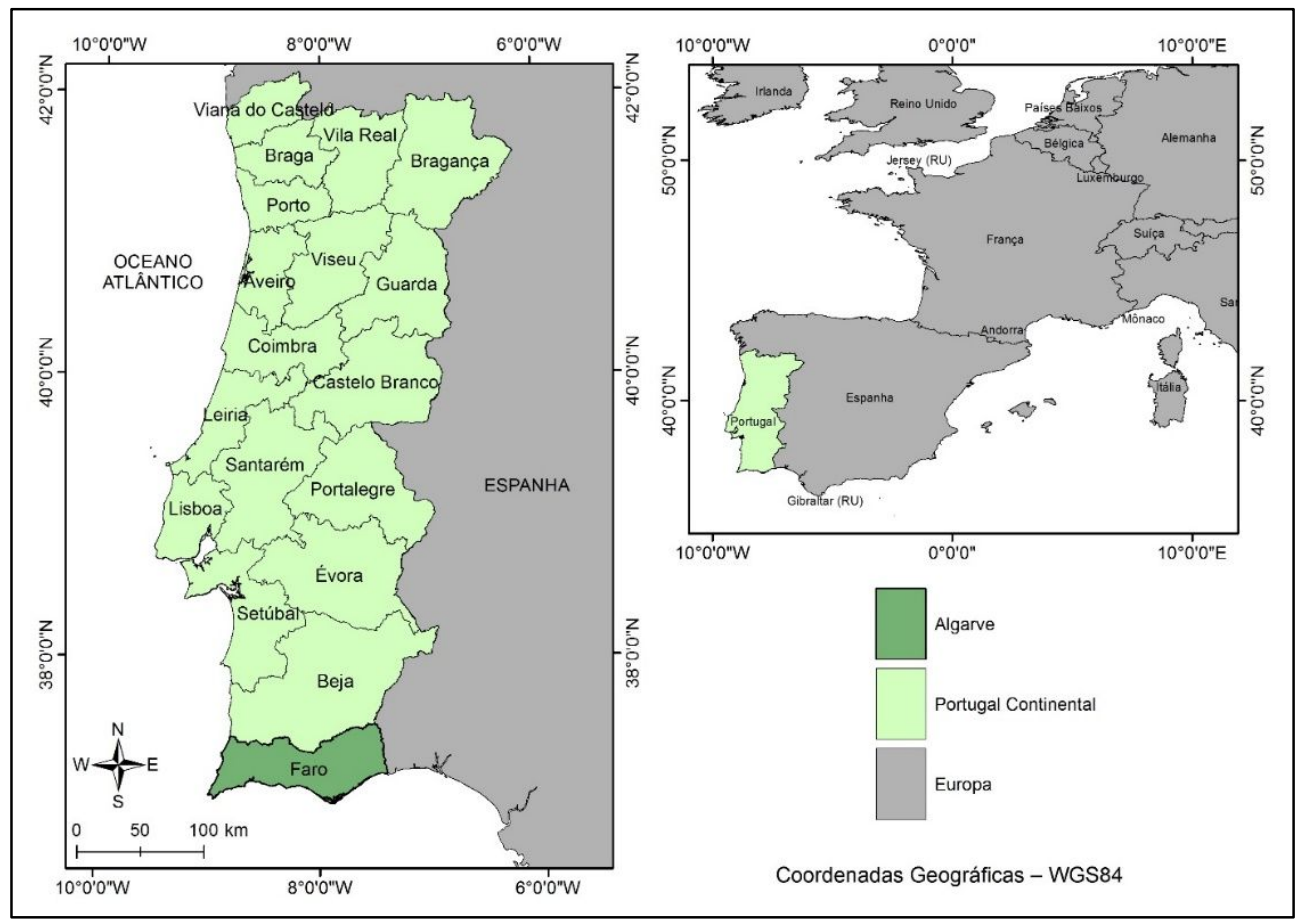

Figura 1. Localização da área de estudo.

Figure 1. Study area location. 


\section{Determinação do potencial de resíduos}

Neste trabalho estimou-se, em ambiente SIG e para a região do Algarve, o potencial de biomassa dos resíduos florestais e de algumas espécies agrícolas selecionadas, bem como a proveniente do corte de matos e de espécies invasoras. Para isso foram utilizadas técnicas de análise espacial que tiveram como base o mapa de uso e ocupação do solo de Portugal de 2015, COS2015 (DIREÇÃO-GERAL DO TERRITÓRIO, 2018) disponibilizado pela Direção-Geral do Território. O mapa COS2015 foi obtido em formato vetorial, em que cada polígono representa unidades de paisagem, baseado em interpretação visual de fotografias aéreas ortorretificadas, com a resolução espacial de $50 \mathrm{~cm}$ e com auxílio de outros dados, tais como séries multitemporais de imagens de satélite. A área mínima considerada é 1 ha com uma escala equivalente 1:25.000. Este mapa tem associada uma nomenclatura constituída por um sistema hierárquico de classes com cinco níveis, possuindo 48 classes ao nível mais detalhado, com unidade cartográfica mínima de 1 ha, exatidão superior a $83 \%$ e exatidão geométrica superior ou igual a 5,5 m (DIREÇÃO-GERAL DO TERRITÓRIO, 2018).

Neste estudo se consideraram apenas resíduos primários, i.e., biomassa obtida diretamente de áreas naturais e plantações (BATIDZIRAI et al., 2012). A metodologia para determinar o potencial de produção de resíduos florestais e parte dos agrícolas (vinha, olival) e da biomassa proveniente do corte de matos e espécies invasoras foi baseada nos estudos de Fernandes; Costa (2010), Viana et al. (2010) e Goméz et al. (2010) em relação à taxa de produção de resíduos para diferentes espécies florestais (dada em t/ha/ano de resíduo seco), utilizando-se também o Inventário Florestal Nacional (IFN5) para estimar os resíduos de povoamentos de espécies invasoras, como as acácias.

Lourinho; Brito (2014) identificaram que as áreas de polígonos obtidas pelo mapa de ocupação do solo não representam a área efetiva ocupada por cada espécie florestal, já que as classes podem conter múltiplas espécies com diferentes graus de cobertura vegetal dentro e entre as classes. A produtividade dos resíduos foi estimada por vários autores a partir do tipo de ocupação do solo, e no caso da ocupação florestal, da composição, estrutura do povoamento e grau de coberto (VIANA et al., 2006; FERNANDES; COSTA, 2010). $\mathrm{Na}$ definição das classes de uso do solo, optou-se por usar as classes do COS2015 pois possibilita diferenciar para a mesma composição, povoamentos florestais de menor e maior densidade, os sistemas agroflorestais e florestais, respectivamente. Também para cada uma das classes é possível pelo grau de coberto, isto é, a Projeção Horizontal da Vegetação (PHV) da cultura principal (proporção da cobertura vegetal atribuída à espécie mais representada) e da cultura secundária de cada classe (porcentagem de cobertura vegetal atribuída à espécie secundária), diferenciar povoamentos que geram mais e menos resíduos (Tabela 1).

A quantidade potencial de resíduos foi obtida a partir de operações de análise espacial, inicialmente em formato vetorial, e posteriormente em formato matricial, utilizando ferramentas do programa ArcGIS, versão 10.2.2 (ESRI, 2010). As diversas classes de uso do solo estão representadas por polígonos que são convertidos para uma grelha de $250 \mathrm{~m}$ de resolução espacial, mantendo a informação da área ocupada por cada classe em cada célula. Obteve-se assim um mapa por cada classe considerada. A estimativa do potencial de biomassa de resíduos para cada espécie foi obtida pelo produto da área ocupada por cada classe, com a respectiva taxa de produtividade residual de cada espécie e com a porcentagem da PHV da espécie principal, as quais estão descritas na Tabela 1 .

Um fator importante a ter em conta quando se pretende analisar a valorização energética da biomassa em uma determinada região é a disponibilidade de biomassa na área 
Tabela 1. Classes do COS2015 consideradas no estudo e seus respectivos valores de Projeção Horizontal da Vegetação (PHV) e produtividade anual de resíduos.

Table 1. Classes of COS2015 considered in the study and their respective values of Horizontal Vegetation Projection (PHV) and annual waste productivity.

\begin{tabular}{|c|c|c|c|}
\hline \multirow[b]{2}{*}{ Classe } & \multicolumn{2}{|c|}{ PHV } & \multirow{2}{*}{$\begin{array}{c}\text { Produtividade de Resíduos } \\
\text { (t seca/ha/ano) }\end{array}$} \\
\hline & $\begin{array}{c}\text { Cultura } \\
\text { principal (\%) }\end{array}$ & $\begin{array}{c}\text { Cultura } \\
\text { secundária }(\%)\end{array}$ & \\
\hline Florestas de azinheira & 20 & - & 0,48 \\
\hline Florestas de castanheiro & 65 & - & 0,50 \\
\hline Florestas de espécies invasoras ${ }^{\star}$ & 65 & - & 20,00 \\
\hline Florestas de eucalipto & 65 & - & 0,88 \\
\hline Florestas de outras folhosas & 65 & - & 0,75 \\
\hline Florestas de outras resinosas & 65 & - & 0,85 \\
\hline Florestas de pinheiro bravo & 65 & - & 1,00 \\
\hline Florestas de pinheiro manso & 65 & - & 0,85 \\
\hline Florestas de sobreiro $^{\star *}$ & 20 & - & 0,48 \\
\hline Matos & 5 & - & 4,00 \\
\hline Olivais & 10 & - & 1,50 \\
\hline Sistemas agroflorestais de azinheira & 27,5 & 27,5 & 0,48 \\
\hline Sistemas agroflorestais de outras espécies & 27,5 & 27,5 & 0,48 \\
\hline Sistemas agroflorestais de outras misturas & 27,5 & 27,5 & 0,48 \\
\hline Sistemas agroflorestais de pinheiro manso & 27,5 & 27,5 & 0,48 \\
\hline Sistemas agroflorestais de sobreiro & 27,5 & 27,5 & 0,48 \\
\hline Sistemas agroflorestais de sobreiro com azinheira & 27,5 & 27,5 & 0,48 \\
\hline Vinhas $^{* * *}$ & 10 & - & 2,19 \\
\hline
\end{tabular}

Notas: Foram considerados os valores estimados por Fernandes; Costa (2010), exceto: ${ }^{\star}$ Estimativa calculada com base no Inventário Florestal Nacional (IFN5) para acácias; ${ }^{\star \star}$ Estimativa obtida por Vieira et al. (2006); ${ }^{\star * \star}$ Estimativa obtida por Gómez et al. (2010).

de coleta em torno da localização geográfica do ponto de consumo. Neste âmbito, utilizando uma grelha de $250 \mathrm{~m}$ de resolução espacial (Mesquita et al., 2018), se mapeou a disponibilidade de biomassa de resíduos florestais e agrícola e de matos obtida pela análise descrita anteriormente em um raio de $30 \mathrm{~km}$ para cada uma das células de uma malha quadrada com $250 \mathrm{~m}$. Pretendeu-se assim conhecer a quantidade de biomassa disponível no Algarve em um raio que se considera economicamente viável para o transporte de biomassa em futuros investimentos em centrais de valorização energética de biomassa. O mesmo raio foi utilizado por López-Rodríguez et al. (2009). Nota-se que a dimensão do raio de coleta que torna economicamente viável o aproveitamento da biomassa depende de uma série de fatores, entre os quais as tecnologias e métodos utilizados para o transporte da biomassa, características do combustível e da região, ou a escala da procura da biomassa. Não foi objetivo deste trabalho procurar a dimensão da área de coleta de biomassa economicamente viável na área de estudo.

\section{Resultados e Discussão}

A Figura 2 apresenta a distribuição espacial do potencial total anual de biomassa residual para o Algarve, considerando as florestas de azinheira, castanheiro, eucalipto, pinheiro bravo, pinheiro manso, sobreiro, entre outras, assim como 


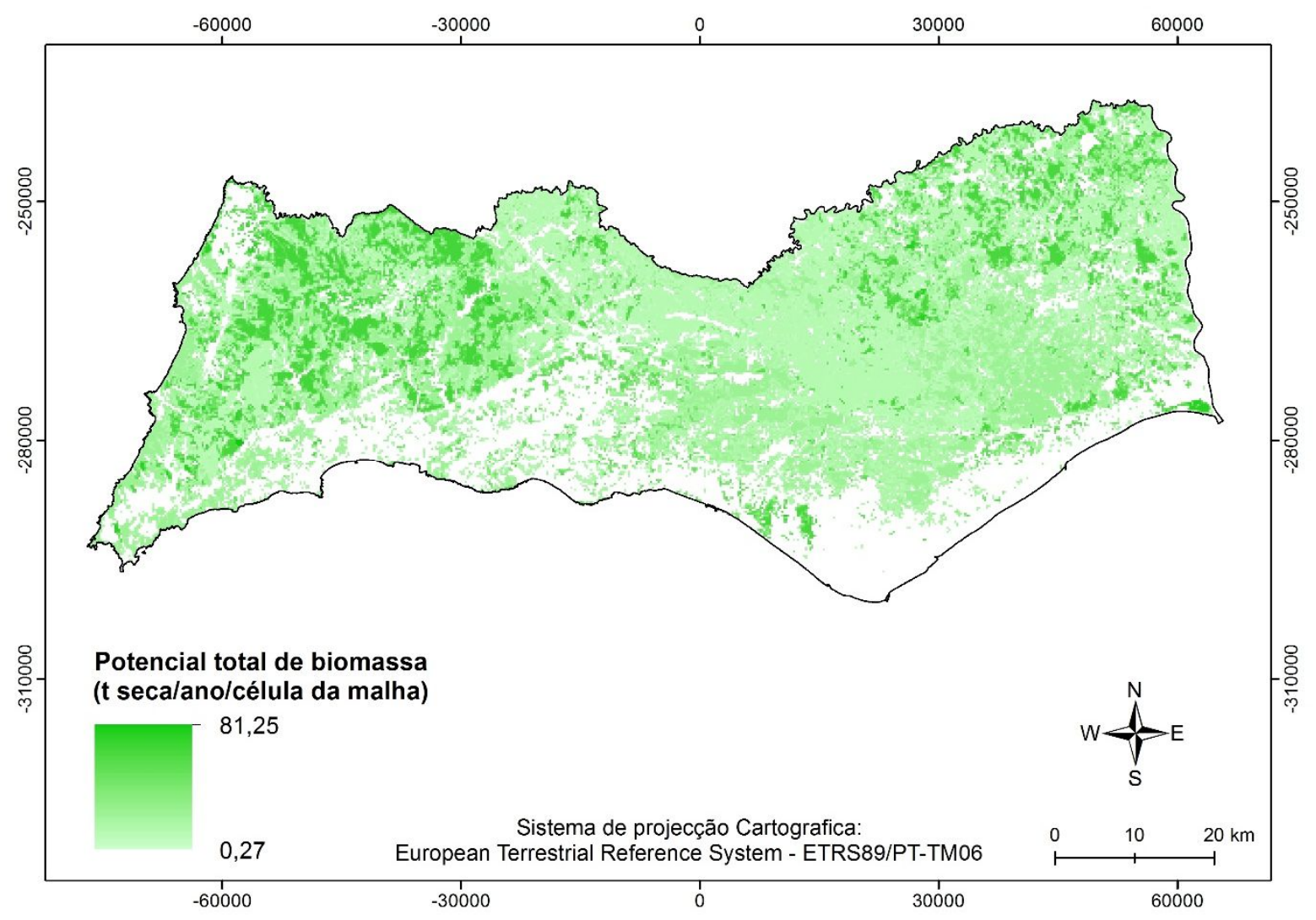

Figura 2. Distribuição do potencial total de biomassa residual disponível para o Algarve ( $\mathrm{t}$ seca/ano/célula da malha).

Figure 2. Distribution of the total residual biomass potential available in the Algarve ( $\mathrm{t}$ dry/year/grid cell).

matos, olivais, vinhas e sistemas agroflorestais de azinheira, pinheiro manso, sobreiro e outras espécies, conforme a Tabela 1. Obteve-se um total de $96.904,8 \mathrm{t}$ seca/ano de biomassa residual para a região do Algarve, sendo as regiões noroeste e nordeste as que apresentam maiores potenciais, alcançando um máximo de $81,25 \mathrm{t}$ seca/ano por célula de 6,25ha. Os sistemas agroflorestais contribuem com um valor de produção total de biomassa pequeno de 1.049,2 $\mathrm{t}$ seca/ano, ou seja, apenas $1,08 \%$.

Ressalta-se que os resultados apresentados correspondem ao potencial de biomassa residual teórico, definido como a totalidade de resíduos produzidos anualmente (VOIVONTAS et al., 2001). Este potencial pode ser considerado um limite superior. Na realidade, a quantidade de biomassa disponível está sujeita a restrições introduzidas por diversos fatores como sejam a utilização dos resíduos para outros fins ou a eficiência de coleta de resíduos. Diversos autores consideram diferentes fatores externos (técnicos, ambientais, ecológicos, económicos e sociais) que influenciam a remoção de resíduos. Não existindo uma padronização para contabilizar a quantidade de biomassa realmente disponível a partir do potencial teórico, estes continuam a ser a única base de comparação entre os diversos estudos (HAMELIN et al, 2019). Por essa razão optou-se por apresentar neste estudo o potencial teórico.

Para os resíduos florestais (Figura 3) se obteve um total de biomassa de 65.543,0 t seca/ano, o que representa $67,6 \%$ do potencial total de biomassa residual disponível para o Algarve. Se destacam as florestas de pinheiro manso com $24.232,8 \mathrm{t} \mathrm{seca} /$ ano e de eucalipto com $18.880,2 \mathrm{t}$ seca/ano, sendo o primeiro concentrado principalmente na região nordeste do Algarve e o segundo na região noroeste. Apesar das florestas de sobreiro ocuparem a maior área dentre as classes da Tabela 1 (72.597,6 ha), estas têm uma 
produtividade menor $(0,48 \mathrm{t}$ seca/ha/ano), mas ainda são responsáveis pela produção de 6.969,4 $\mathrm{t}$ seca/ano de biomassa. As florestas de azinheira têm um potencial de biomassa residual de 2.010,4 t seca/ano, de castanheiro de apenas 5,8 tseca/ano e de pinheiro bravo de 4.059, $4 \mathrm{t} \mathrm{seca/ano.} \mathrm{As} \mathrm{florestas} \mathrm{de} \mathrm{eucalipto,} \mathrm{de} \mathrm{pinheiro}$ manso e de sobreiro representam, respectivamente, 19,5\%, $25,0 \%$ e $7,2 \%$ do potencial total.

Viana et al. (2010) utilizaram dados do Inventário Florestal Nacional de 2005/06 para realizar uma estimativa da quantidade total de biomassa residual de florestas de pinheiro-bravo e de eucalipto para Portugal. Para a região do Algarve os autores obtiveram valores médios e máximos de $8.829,1 \mathrm{t}$ /ano e $11.510,5 \mathrm{t} /$ ano, respectivamente, enquanto que no presente estudo se obteve quase o dobro do valor máximo de Viana et al. (2010), com um total de 22.939,5 t/ano para a soma do total de biomassa residual das duas espécies de florestas. As estimativas divergem pois há diferença de quase 10 anos entre os dados baseados em cada estudo, além de que a equação de cálculo foi diferente, dado que os autores utilizaram equações alométricas ao nível da árvore e métodos de extrapolação e pesos diferentes para cada espécie florestal.

Como é possível observar pela Tabela 1 e pela Figura 4, os matos estão presentes de maneira dispersa em uma área significativa do Algarve e apresentam uma boa produtividade de resíduos ( $4 \mathrm{t}$ seca/ha/ano), contribuindo então com uma produção de 26.321,6 t seca/ano de biomassa (27,2\%). Este valor demonstra que é uma boa fonte de biomassa para valorização energética. A remoção de matos esclerófitos é proposta por exemplo por Malico et al. (2016) com vista à redução da carga combustível e consequente prevenção de incêndios florestais. Este tipo de vegetação não apresenta uma importância ecológica elevada, contribuindo a sua remoção para o aumento da biodiversidade (MALICO et al., 2016).

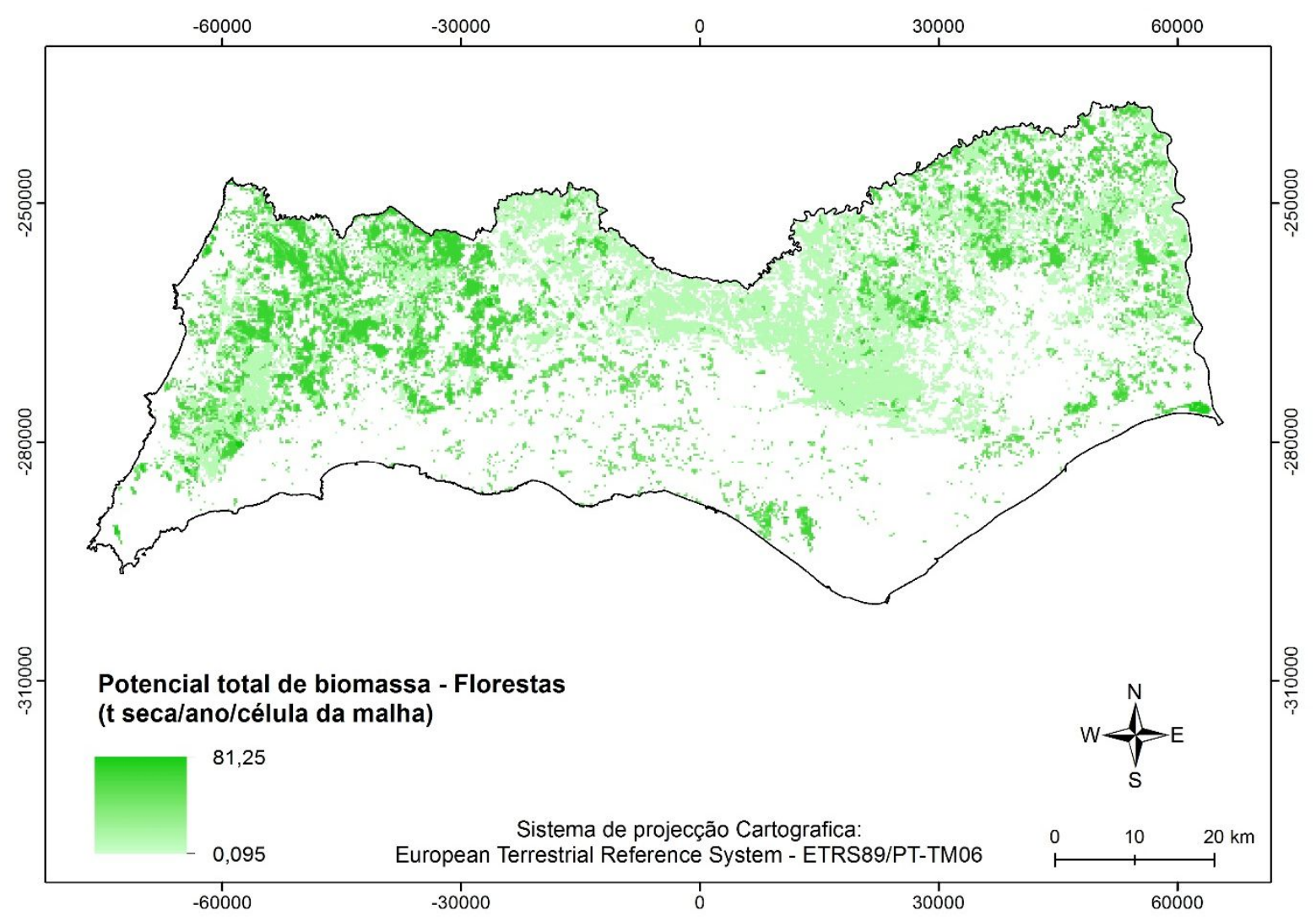

Figura 3. Distribuição do potencial de biomassa residual das florestas disponível para o Algarve (t seca/ano/célula da malha). Figure 3. Distribution of residual biomass potential of the forests available in the Algarve (t dry/year/grid cell). 


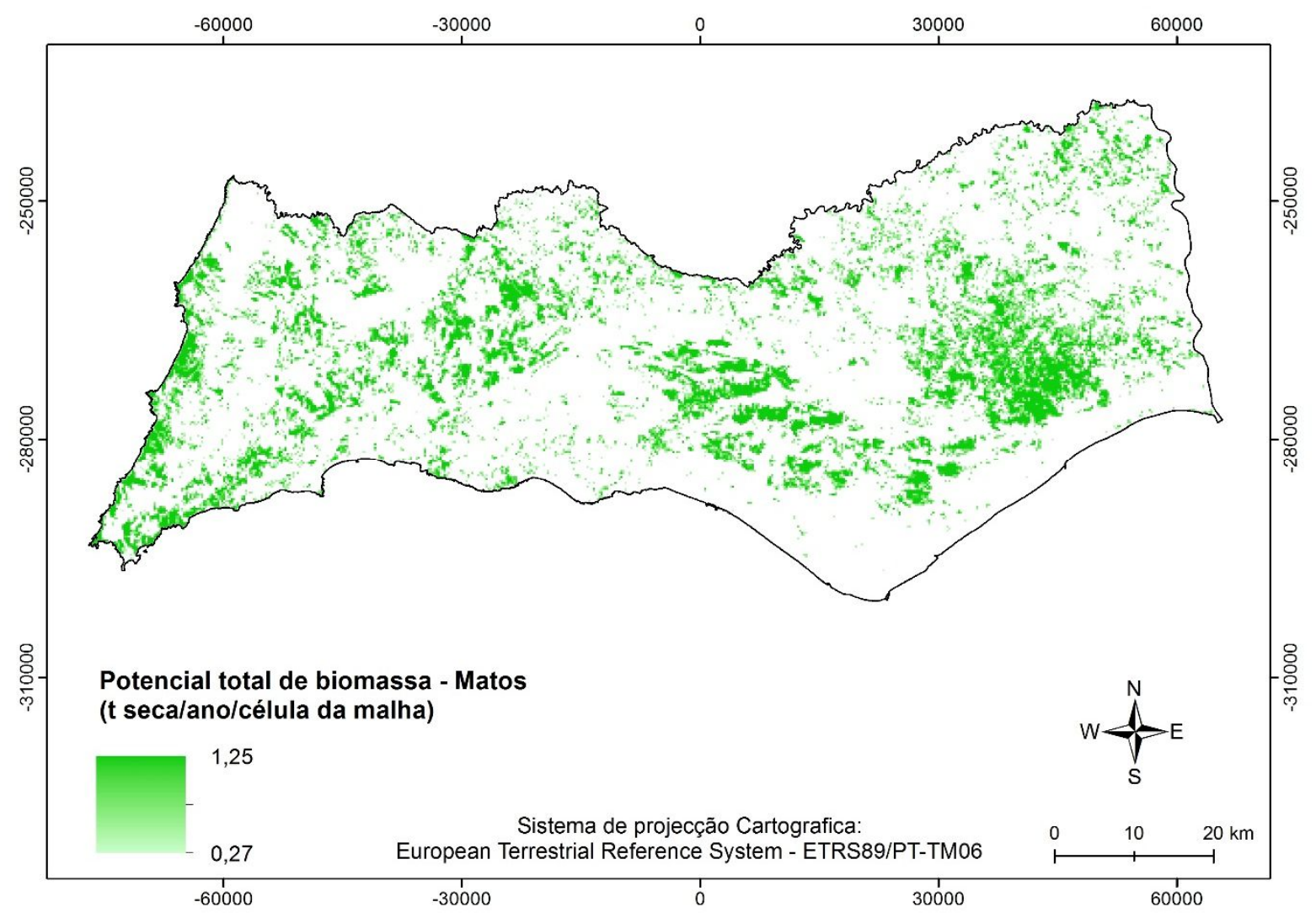

Figura 4. Distribuição do potencial de biomassa residual dos matos disponível para o Algarve (t seca/ano/célula da malha).

Figure 4. Distribution of residual biomass potential of the weeds available in the Algarve (t dry/year/grid cell).

Quanto aos resíduos agrícolas, os olivais e as vinhas (Figura 5) apresentam uma produção de 3.693,3 e 297,6 t seca/ano de biomassa, respectivamente, representando juntos $4,12 \%$ do total da biomassa residual disponível. Os resíduos agrícolas apresentam duas vantagens do ponto de vista da obtenção de biomassa para energia: são produzidos anualmente ou em ciclos curtos (2-3 anos), dado que são gerados a partir de operações agrícolas, nomeadamente as podas; e estão concentrados no espaço, dado que frequentemente os resíduos das podas são normalmente concentrados num local para posterior remoção ou destruição.

A Figura 6 apresenta o potencial de biomassa residual acumulado assumindo um raio de coleta de $30 \mathrm{~km}$ ao redor de cada célula considerada, variando este potencial entre 6 e $33 \mathrm{kt}$ seca/ano. A região com maior potencial de biomassa disponível no Algarve está localizada na região centro-oeste, sendo essa a única zona que alcança valores acumulativos de 30 a $33 \mathrm{kt} \mathrm{seca/ano} \mathrm{em} \mathrm{um} \mathrm{raio} \mathrm{de} 30 \mathrm{~km}$. Esses valores estão relacionados com a presença de florestas de eucalipto e matos.

Nos extremos da região sul tem-se valores acumulados abaixo de 10 kt/ano, uma vez que esta é constituída por áreas de zonas úmidas e há limitações físicas devido à presença do oceano. A fronteira oeste faz limite com o oceano, assim, a biomassa acumulada obtida foi baixa. Refira-se que, tal como apontado por Mesquita et al. (2018), o uso do raio de $30 \mathrm{~km}$ pode criar falsos efeitos de corte no mapa final, impostos pelo limite da área de estudo, neste caso na fronteira a norte com a região do Alentejo e a leste com a Espanha (embora esta última se trate de uma fronteira territorial e, portanto, poderão haver verdadeiras limitações à recolha de biomassa).

A análise da biomassa total disponível em uma determinada área de coleta apresentada neste trabalho permite identificar, do ponto de vista do recurso, quais as me- 


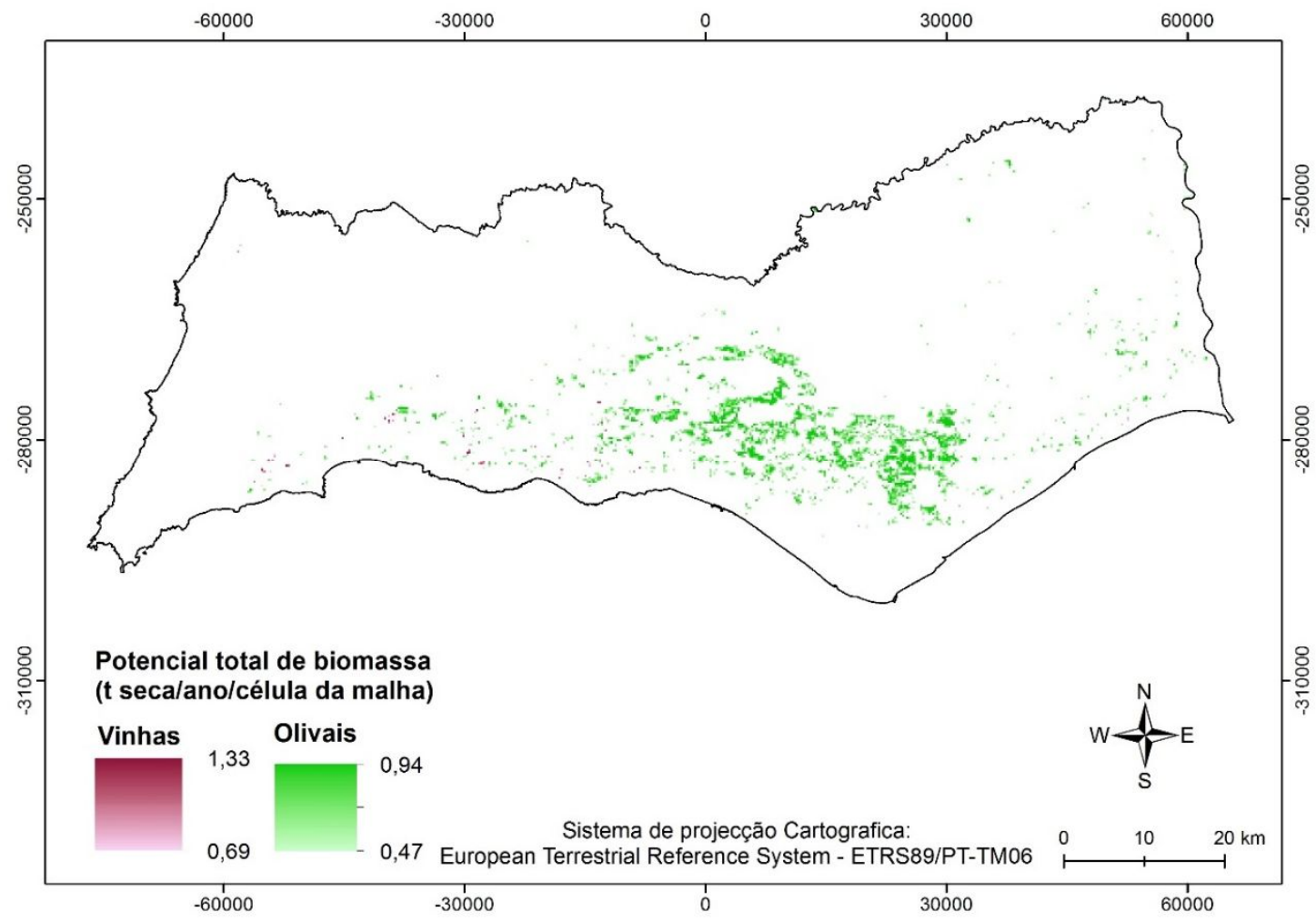

Figura 5. Distribuição do potencial de biomassa residual dos olivais e das vinhas disponível para o Algarve ( $\mathrm{t}$ seca/ano/célula da malha).

Figure 5. Distribution of residual biomass potential of olive groves and vineyards available in the Algarve (t dry/year/grid cell).

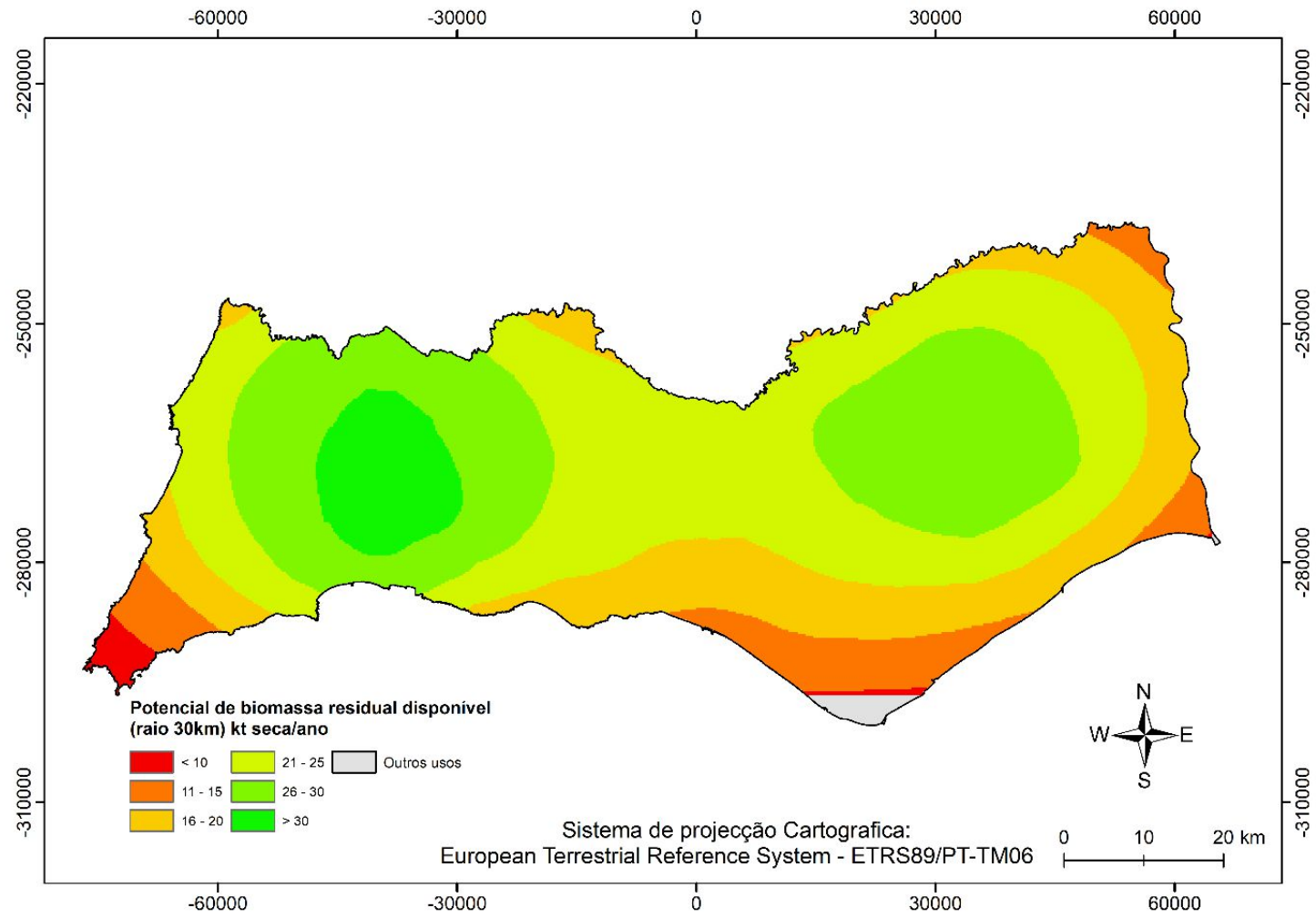

Figura 6. Potencial de biomassa residual disponível numa área de coleta com raio de $30 \mathrm{~km}$ em torno de cada ponto da malha para o Algarve (kt seca/ano).

Figure 6. Residual biomass potential available within a collection area with a $30 \mathrm{~km}$ radius around each grid point in the Algarve (dry kt/year). 
lhores localizações para centrais de energia a biomassa. Observando a Figura 6, as melhores localizações seriam as zonas centro-oeste e centro-leste do Algarve. Nessas duas regiões a quantidade de biomassa potencial permite a instalação de pequenas/médias centrais de biomassa, inexistentes na região. Estava prevista a instalação de uma central termelétrica a biomassa na região centro-oeste do Algarve (VIANA et al., 2006), mas ainda não se sucedeu.

\section{Conclusões}

Com a avaliação do potencial da biomassa dos resíduos florestais e agrícolas, e de matos e espécies invasoras por meio do ArcGIS, foi possível estimar um total de aproximadamente 97 kt seca/ano na região do Algarve, proveniente principalmente das florestas de pinheiro manso e de eucalipto, bem como dos matos. Ainda, obteve-se valores de biomassa residual acima de $30 \mathrm{kt}$ seca/ano para uma área de coleta de raio de $30 \mathrm{~km}$, destacando-se a região centro-leste do Algarve. Estas quantidades justificam uma análise mais detalhada sobre a viabilidade de implementar projetos de valorização energética dessa biomassa na região, indicando que existe biomassa disponível para essa valorização em pequena ou média escala.

Constatou-se que o método baseado em SIG usado pode ser uma ferramenta pertinente para avaliar a distribuição espacial de biomassa residual para grandes áreas geográficas, bem como seu potencial, o que pode ser útil para se obter conclusões preliminares que facilitam a decisão para um modelo mais detalhado. Ressalta-se a importância de um estudo aprofundado sobre a produtividade dos resíduos das diferentes espécies de interesse, pois os mesmos influenciam fortemente o total de produção de biomassa, por isso é imprescindível obter valores bem fundamentados e condizentes com a realidade da região e a espécie, por exemplo.

\section{Agradecimentos}

Os autores agradecem ao Paulo Mesquita pelo apoio disponibilizado nos procedimentos realizados no ArcGIS.

\section{Referências}

ALFONSO, D.; PERPIÑÁ, C.; PÉREZ-NAVARRO, A.; PEÑALVO, E.; VARGAS, C.; CÁRDENAS, R. Methodology for optimization of distributed biomass resources evaluation, management and final energy use. Biomass and Bioenergy, v. 33, p. 1070-1079, 2009.

BATIDZIRAI, B.; SMEETS, E.M.W.; FAAIJ, A.P.C. Harmonising bioenergy resource potentials Methodological lessons from review of state of the art bioenergy potential assessments. Renewable and Sustainable Energy Reviews, v. 16, p. 6598-6630, 2012.

BRASIL, A. C. M.; BRASIL, A.; MALICO, I. Evaluation of the Electrical Energy Potential of Woody Biomass in the Near Region of the Hydropower Plant Tucuruí-Brazil. Waste and Biomass Valorization, p. 1-11, 2018.

DGEG, Direcção Geral de Energia e Geologia. Renováveis. Estatísticas rápidas, nº 168, out. 2018.

DIREÇÃO-GERAL DO TERRITÓRIO. Carta de Uso e Ocupação do Solo de Portugal Continental para 2015 (COS2015v1.0). Lisboa, 2018. Conjunto de Dados Geográficos. Escala 1:25.000

ESRI, 2010. ArcGIS Desktop: Release 10.

EUROSTAT. Energy Balance Sheets, 2016 Data, 2018 Edition. Luxembourg: Publications Office of the European Union, 2018.

WILLIAMS, CAROL L.; DAHIYA, A.; PORTER, P. Introduction to bioenergy. In: Dahiya, A. (Ed.), Bioenergy: Biomass to biofuels. Academic Press, p. 5-36, 2015.

FERNANDES, U.; COSTA, M. Potential of biomass residues for energy production and utilization in a region of Portugal. Biomass and Bioenergy, v. 34, p. 661-666, 2010.

GÓMEZ, A.; RODRIGUES, M.; MONTAÑÉS, C.; DOPAZO, C.; FUEYO, N. The potential for electricity generation from crop and forestry residues in Spain. Biomass and Bioenergy, v. 34, p. 703-719, 2010. 
HAMELIN, L.; BORZ• CKA, M.; KOZAK, M.; \& PUDE• KO, R. A spatial approach to bioeconomy: Quantifying the residual biomass potential in the EU-27. Renewable and Sustainable Energy Reviews, v. 100, p. 127-142, 2019.

ICNF, Instituto da Conservação da Natureza e das Florestas. IFN6 - Áreas dos usos do solo e das espécies florestais de Portugal continental. Resultados preliminares. Lisboa, 2013. $34 \mathrm{p}$.

LOURINHO, G.; BRITO, P. Assessment of biomass energy potential in a region of Portugal (Alto Alentejo). Energy, v. 81, p. 189-201, 2014.

LÓPEZ-RODRÍGUEZ, F.; ATANET, C. P.; BLÁZQUEZ, F. C.; CELMA, A. R. Spatial assessment of the bioenergy potential of forest residues in the western province of Spain, Caceres. Biomass and Bioenergy, v. 33, p. 1358-1366, 2009.

MALICO, I.; CARRAJOLA, J.; GOMES, C. P.; LIMA, J. Biomass residues for energy production and habitat preservation. Case study in a montado area in Southwestern Europe. Journal of Cleaner Production, v. 112, p. 36763683,2016

MESQUITA, P.; PEREIRA, R. P.; MALICO, I.; GONÇALVES, A. C.; SOUSA, A. O. M. GIS based analysis of potential forest residues for energy in Alentejo, Portugal. International Sustainable Energy Conference 2018, Graz, Áustria, 3-5 out. 2018.

REN21. Renewables 2017 Global status report. REN21 Secretariat, Paris, 2017.

TAIBI, E.; GIELEN, D.; BAZILIAN, M. The potential for renewable energy in industrial applications. Renewable and Sustainable Energy Reviews, v. 16 (1), p. 735-744, 2012.

UE. Directiva 2009/28/CE do Parlamento Europeu e do Conselho, de 23 de abril de 2009. Dispõe sobre a utilização de energia proveniente de fontes renováveis. Jornal Oficial das Comunidades Europeias, Bruxelas, v. 140, p. 16-62, jun. 2009.

VIANA, H.; COHEN, W.B.; LOPES, D.; ARANHA, J. Assessment of forest biomass for use as energy. GIS-based analysis of geographical availability and locations of woodfired power plants in Portugal. Applied Energy, v. 87, p. 2551-2560, 2010.
VOIVONTAS, D.; ASSIMACOPOULOS, D.; KOUKIOS, E.G. Assessment of biomass potential for power production: a GIS based method. Biomass and Bioenergy, v. 20, p. 101$112,2001$. 